\title{
A cidadania na formação de jovens do Ensino Médio na dimensão das metodologias de ensino
}

The citizenship in the training of High School students in the dimension of teaching methodologies Ciudadanía en la formación de jóvenes de Secundaria en la dimensión de metodologías de enseñanza

\section{Resumo}

O presente estudo teve como objetivo analisar os desdobramentos da cidadania na formação de jovens do ensino médio na dimensão das metodologias de ensino e fazer docente. Caracteriza-se como qualitativo descritivo e interpretativo. Foram selecionadas 2 escolas de ensino médio, uma da rede de ensino pública (escola A) e uma da rede privada (escola B) de uma cidade do Vale do Sinos/RS, Brasil. Para a coleta de dados foram utilizados análise de documento (PPP), observações, diários de campo e entrevistas com equipe diretiva e docentes, por meio da ferramenta bola de neve. Compreendemos que na escola A, o método tradicional de ensino torna as conexões, contextualizações, criticidade e reflexões mais limitadas. Portanto, a formação da cidadania se constitui através do enquadramento do comportamento social e na preparação para o trabalho. Na escola B, os métodos ativos e colaborativos promovem a formação de um aluno crítico, reflexivo e com mais autonomia.

Palavras-chave: Escola; Educação; Cidadão; Metodologias de ensino; Ensino.

\section{Abstract}

The present study aimed at analyzing the unfolding of citizenship in the training of high school students in the dimension of teaching methodologies and teaching itself. It is characterized as qualitative descriptive and interpretative. Two high schools were selected, one is public (school A) and the other is private (school B), both located in a city in Vale dos Sinos/RS, Brasil. For data collection, we used the document analysis (PPP), observations, field journals and interviews with the directive team and teachers, through snowball sampling. We realized that in school A, the connections, contextualization, criticism and reflections are more limited due to the traditional method of teaching. Therefore, the formation of citizenship constitutes itself through the framing of social behavior and in the preparation for work. In school B, the active and collaborative methods foster the training of discerning, reflective and more autonomous students.

Keywords: School; Education; Citizen; Teaching methodologies; Teaching.

\section{Resumen}

Este estudio tuvo como objetivo analizar el desarrollo de la ciudadanía en la formación de jóvenes de secundaria en la dimensión de las metodologías didácticas y actuación docente. Se caracteriza como cualitativo, descriptivo e interpretativo. Fueron seleccionadas dos escuelas de nivel secundario, una de la red pública de educación (escuela A) y otra de la red privada (escuela B), ubicadas en una ciudad de Vale do Sinos/RS, Brasil. Para la recolección de datos se utilizaron análisis de documento (PPP), observaciones, diarios de campo y entrevistas con el equipo directivo y profesores a través de la herramienta bola de nieve. Se comprende que en la escuela A, el método tradicional de enseñanza resulta en conexiones, contextualizaciones, criticidad y reflexiones más limitadas. Por lo tanto, la formación de la ciudadanía se constituye enmarcando el comportamiento social y preparándose para el trabajo. En la escuela B, los métodos activos y colaborativos promueven la formación de un alumno crítico, reflexivo y autónomo.

Palabras clave: Escuela. Educación. Ciudadano. Metodologías de enseñanza; Enseñanza. 


\section{Introdução}

(Re)pensar a educação e a escola é um movimento que ocorre há muito tempo em nível mundial. John Dewey, quase cem anos atrás, nos provocava a refletir e pensar a escola como um "laboratório da vida", tomando como base as experiências concretas de mundo. Portanto, o "princípio de que o desenvolvimento da experiência se faz por interação do indivíduo com pessoas e cousas significa que a educação é, essencialmente, um processo social" (Dewey, 1976, p. 54). Entendendo a educação como um processo social, pode-se afirmar que a escola precisa estar atenta e comprometida com sua função social de desenvolvimento e formação do sujeito de forma integral. "A instituição educacional é uma das e, talvez, a mais importante responsável pela formação ética do indivíduo. Formação essa significativa para se exercer a cidadania de fato." (Pereira; Silva, 2008). No Brasil, o "Manifesto pela Educação" reconheceu a necessidade dessa formação integral, evidenciando "valores respeitosos à diversidade e aos direitos de todas as pessoas do mundo", com destaque "à tolerância, à solidariedade, à valorização da diversidade, ao respeito aos direitos humanos, aos cuidados com o meio ambiente e a ênfase à participação cidadã e democrática, bandeiras históricas da Educação Cidadã” (Padilha, 2009, p. 9).

A educação cidadã vem num movimento contrário ao que presenciamos atualmente em plano mundial e de Brasil, onde a concepção neoliberal de desenvolvimento, a meritocracia e a lógica mercadológica buscam permanentemente se sobrepor a qualquer interesse. A educação cidadã, reconhecida no Brasil e em outros países, é concebida como aquela que "visa à sustentabilidade social, afetiva, educacional, cultural, ambiental, econômica e política, consagrando-se como a perspectiva mais avançada do nosso tempo" (Padilha, 2009, p. 9).

Nesse sentido, compartilhamos de alguns questionamentos trazidos por alguns autores acerca da formação dos alunos, pensando na função social da escola de desenvolvê-los de forma integral, isto é, a formação da/para a cidadania. Dewey (1976, p. 15) nos provoca a pensar quantos alunos

[...] adquirem habilidades por meio de exercícios de automatismo e assim limitam a capacidade de julgar e agir inteligentemente em situações novas? [...] Quantos acharam o que aprenderam tão alheio às situações de vida fora da escola, que nenhuma capacidade de controle puderam desenvolver para o comando da vida?

Enquanto que Padilha (2009, p. 10) indaga:

De que adiantaria uma pessoa bem formada, bem intencionada e até mesmo "bem sucedida" economicamente, se esta pessoa for alienada, insensível aos problemas sociais, locais e planetários, e não tiver o menor cuidado ou respeito com o mundo à sua volta - ou seja, nem com as pessoas, nem com o uso da água, nem com a poluição do ar etc.? De que adianta ser um profissional formado na melhor universidade do planeta, se ele for arrogante, preconceituoso, se não for capaz de conviver ética e respeitosamente com outras pessoas e com as diferentes culturas?

Romper com essa lógica atrelada ao individualismo e ao mercado, a reprodução e alienação, bandeiras do neoliberalismo, são necessárias na busca de uma educação de qualidade, ou seja, "uma educação cidadã, ativa, participativa, formando para e pela cidadania, empoderando pessoas e comunidades" (Gadotti, 2009, p. 56, grifo do autor).

Isto posto, torna-se importante a discussão acerca da formação da cidadania no âmbito escolar, buscando compreender de que forma a mesma se desdobra nesse contexto. Por ser um conceito polissêmico, cabe destacar que nesse texto tratamos a cidadania como prática cotidiana, isto é, uma "cidadania em construção", que preconiza a "valorização da dimensão processual na qual o resultado final não se reporta já a uma noção fixa de cidadania, ou a um modo preestabelecido de agir como ou ser cidadão/cidadã", mas sim uma problematização e construção da sua própria cidadania (Menezes; Ferreira, 2014, p. 135). Portanto, nesse caso a cidadania

[...] não deve ser vista apenas como um status que se conquista após a passagem por determinadas experiências, mas como um processo de legitimação de formas de ser e fazer que desde sempre cada indivíduo exercita ao longo de sua trajetória de vida, em um movimento de autorreflexão permanente (Maia; Pereira, 2014, p. 623, grifo das autoras).

Deste modo, o presente estudo teve como objetivo analisar os desdobramentos da cidadania na formação de jovens do 
ensino médio na dimensão das metodologias de ensino e fazer docente em uma escola pública (escola A) e em uma escola privada (escola B) de uma cidade do Vale do Sinos/RS . Sendo assim, a pesquisa apresenta questões relativas às metodologias utilizadas e ao fazer docente do campo escolar relacionado à cidadania nos contextos estudados, relacionado ao trabalho coletivo e como a cidadania é desenvolvida, através do pensar e agir na escola por meio do fazer docente.

\section{Metodologia}

Este estudo caracterizou-se como qualitativo descritivo e interpretativo. A pesquisa qualitativa tem recursos para descrever como o fenômeno é localmente constituído (Silverman, 2009), no caso desta pesquisa, como as metodologias de ensino e o fazer docente abordaram a cidadania em uma escola pública (escola A) e em uma escola privada (escola B) de uma cidade do Vale dos Sinos/RS.

Foram selecionadas duas escolas, uma da rede de ensino pública, chamada nesse estudo de escola A, e uma da rede privada da cidade, chamada como escola $\mathrm{B}$, tendo como critério de escolha as escolas com maior número de alunos matriculados no Ensino Médio no ano de 2018, presumindo-se, assim, que essas eram as escolas mais procuradas e com maior alcance quantitativo na formação dos alunos da respectiva cidade, atuais/futuros cidadãos.

A imersão no campo empírico se constituiu através de observações, registradas em diários de campo, entrevistas e documentos. Os documentos analisados foram os Projetos Político-Pedagógicos (PPP) das escolas participantes do estudo. Entretanto, a escola B tinha uma versão do PPP de 2007 em seu site e a mesma não estava atualizada, principalmente porque a escola modificou toda sua metodologia e, por orientação da direção da escola, esse PPP deveria ser desconsiderado, já que o novo estava sendo construído e não pôde ser fornecido, pois não era de domínio público. Dessa forma, fomos orientados a utilizar o que estava no guia do aluno e também no site.

As observações nas escolas ocorreram no período e turnos conforme o quadro 1, duas vezes por semana em cada escola.

Quadro 1 - Observações nas escolas.

\begin{tabular}{|c|c|c|}
\hline & Escola A & Escola B \\
\hline Data inicial & 13 de março de 2018 & 21 de março de 2018 \\
\hline Data final & 13 de junho de 2018 & 14 de junho de 2018 \\
\hline Turnos observados & $\begin{array}{c}\text { Manhã: } 2^{\circ} \text { e } 3^{\circ} \text { anos } \\
\text { Tarde: } 1^{\circ} \text { anos }\end{array}$ & Manhã: $1^{\text {o }}, 2^{\circ}$ e $3^{\circ}$ anos \\
\hline
\end{tabular}

Fonte: Elaborado pelos autores.

As entrevistas foram realizadas com um membro da equipe diretiva e dois docentes de cada escola, indicados por meio da ferramenta bola de neve que "utiliza cadeias de referência" para que os "novos contatos" tenham "as características desejadas" (Vinuto, 2014, p. 203), conforme o quadro abaixo: 
Quadro 2 - Codificação das entrevistas.

\begin{tabular}{|c|c|c|c|c|}
\hline Função & Pseudônimo & Escola & Data & Tempo de entrevista \\
\hline Supervisora & Julia & A & $12 / 07 / 2018$ & $-^{1}$ \\
\hline Professora & Eliza & A & $10 / 07 / 2018$ & $55 \mathrm{~min} 28 \mathrm{seg}$ \\
\hline Professora & Celia & A & $12 / 07 / 2018$ & $42 \mathrm{~min} 09 \mathrm{seg}$ \\
\hline Diretora & Lorena & B & $9 / 07 / 2018$ & $55 \mathrm{~min} 28 \mathrm{seg}$ \\
\hline Professor & Leonel & B & $9 / 07 / 2018$ & 1 hora03min59seg \\
\hline Professor & Edvaldo & B & $9 / 08 / 2018$ & $37 \mathrm{~min} 08 \mathrm{seg}$ \\
\hline
\end{tabular}

Fonte: Elaborado pelos autores.

A presente pesquisa seguiu os parâmetros éticos conforme Resolução 510/2016 do Conselho Nacional de Saúde, ciente sobre as obrigações éticas, preservando o respeito às pessoas. Foi aprovada pelo Comitê de Ética em Pesquisa da Universidade Feevale, sob o número 81015617.1.0000.5348.

Para a análise e interpretação dos dados, utilizou-se a triangulação que, neste estudo, ocorreu através da triangulação por fontes, teórica e reflexiva (Cauduro, 2004). Ou seja, os dados provenientes das entrevistas, observações/diários de campo e PPP foram confrontados, juntamente com o aporte teórico e reflexão sobre os achados.

\section{Resultados e Discussão}

Buscando analisar os desdobramentos da cidadania na formação de jovens do ensino médio na dimensão das metodologias de ensino e fazer docente em uma escola pública (escola A) e em uma escola privada (escola B) de uma cidade do Vale do Sinos/RS, verificamos várias diferenças que são apresentadas primeiramente no quadro 3 e analisadas descritivamente na sequência.

Quadro 3 - Síntese dos elementos de análise.

\begin{tabular}{|l|l|l|}
\hline $\begin{array}{l}\text { Elementos de observação do } \\
\text { cotidiano escolar }\end{array}$ & Escola A & Escola B \\
\hline Abordagem e metodologia de ensino & Tradicional. & Ativa e colaborativa. \\
\hline Como trabalham com a cidadania & $\begin{array}{l}\text { No sentido de enquadramento do } \\
\text { comportamento social e na busca para a } \\
\text { preparação para o trabalho. }\end{array}$ & $\begin{array}{l}\text { Na busca de formar um aluno questionador, } \\
\text { crítico, solucionador de problemas, criativo, } \\
\text { inovador e que interaja com a diferença. }\end{array}$ \\
\hline $\begin{array}{l}\text { Trabalham de forma coletiva para } \\
\text { desenvolver a cidadania }\end{array}$ & $\begin{array}{l}\text { Pensando no que foi citado acima sim, mas } \\
\text { na cidadania que o estudo defende não, } \\
\text { somente uma professora de sociologia se } \\
\text { destaca. }\end{array}$ & $\begin{array}{l}\text { Sim, apesar de no cotidiano (poucos) } \\
\text { docentes ficarem à parte, demonstrando } \\
\text { dificuldade ou falta de interesse sobre a } \\
\text { questão. }\end{array}$ \\
\hline Fazer docente & $\begin{array}{l}\text { Separadas por disciplinas, aulas } \\
\text { expositivas, nas quais o professor é o } \\
\text { detentor do conhecimento. }\end{array}$ & $\begin{array}{l}\text { Em alguns momentos é interdisciplinar, por } \\
\text { projetos, os professores são facilitadores dos } \\
\text { conteúdos. Atividades de resolução de } \\
\text { conflitos, aluno é central no processo. }\end{array}$ \\
\hline
\end{tabular}

Fonte: Elaborado pelos autores.

\footnotetext{
${ }^{1}$ Supervisora não quis que a entrevista fosse gravada, portanto somente anotamos as respostas.
} 
Como exposto no quadro 3, os contextos pesquisados apresentaram diferenças significativas nos desdobramentos da cidadania, entretanto, antes de adentrar nas análises descritivas desses aspectos, há um ponto interessante que merece atenção e pode servir de exemplo para projetos posteriores em outros locais. A escola B, como apresentado no quadro 3, utiliza a abordagem e metodologia ativa e colaborativa ${ }^{2}$, que foi implementada no local no início de 2018 (momento que se iniciou a pesquisa de campo) e, juntamente com a mudança da metodologia e do funcionamento do cotidiano escolar como um todo, a escola iniciou também um projeto chamado "mãos dadas". Esse projeto ocorria nas segundas e quintas, no primeiro período da manhã, no qual alunos e professores dialogavam sobre questões pessoais e do grupo, envolvendo questões psicológicas e emocionais dos alunos (além das questões de ensino-aprendizado). Cada professor era responsável por um grupo determinado no início do ano. Os efeitos desses encontros foram percebidos no decorrer do ano letivo, tanto no que tange às questões de aprendizagem, como questões do convívio social e andamento do cotidiano escolar, pois, assim, os alunos tinham maior possibilidade de se conhecer, trocar experiências, falar sobre seus anseios, ou seja, a escola dava voz e vez para os alunos, processo importante para o desenvolvimento e construção da cidadania. Como exemplo prático desse projeto, temos uma atividade proposta pelo professor de sociologia, que era responsável pelo grupo que estava sendo observado no dia 26 de março de 2018. O docente fez uma dinâmica para aproximar os alunos, já que alguns nunca haviam se falado (de acordo com ele). A atividade era escrever num papel uma pergunta anônima a qualquer pessoa da sala, que poderia ser específica ou geral, depois os alunos tiravam as questões e iam respondendo. O interessante foi ver os alunos perceberem que os colegas tinham pontos de vista e objetivos de vida distintos e trazerem elementos que contribuíam para que pensassem a respeito. Como exemplo temos a questão feita "qual sua meta para o futuro?". Alguns colegas já haviam falado em morar fora do país e, então, uma menina respondeu o seguinte "me formar, continuar morando no Brasil, tentar fazer a diferença para que as coisas mudem, ao invés de ficar reclamando" (diário de campo, 26/03/2018). Os colegas ficaram reflexivos e ao longo da atividade o professor mediava os desdobramentos dessa fala.

Outra questão trabalhada nesse projeto foi a mudança de abordagem e metodologia pela qual a escola passava. No começo das observações se percebeu que os $1^{\circ}$ anos do ensino médio não levavam as combinações muito a sério, talvez pela imaturidade ou pelo momento de transição do ensino fundamental para o ensino médio, percebendo-se certo grau de afirmação dos jovens. Os alunos apresentavam dificuldade de compreender os novos arranjos metodológicos e premissas pedagógicas da escola, pouco se engajando nas atividades propostas. Isso foi muito trabalhado pelos professores durante as aulas e nos horários do projeto "mãos dadas". No dia 18 de maio, durante o recreio na sala dos professores, um docente de matemática comentou "Eu acho que já está surgindo efeito da conversa do mãos dadas. [...] Sala cheia, todo mundo trabalhando. A gente não pode deixar a peteca cair e estar sempre reforçando no mãos dadas" (diário de campo, 18/05/2018). Ou seja, apesar da dificuldade encontrada no início em função do rompimento da cultura escolar ${ }^{3}$ presente até então, os docentes persistiram no diálogo com os alunos, o que resultou na melhora da participação e responsabilidade dos alunos, que avançaram na compreensão que o ensino é algo para eles, para a formação de sua cidadania. Mesmo assim os docentes precisavam estar em constante comunicação com os discentes a respeito de seus direitos e deveres, pois ainda permaneciam impasses em determinados momentos, nos quais os professores precisavam chamar atenção dos alunos, pedir para deixarem o celular, controlar presença em sala de aula, entre outras demandas que fazem parte do cotidiano escolar.

Nesse contexto, constatou-se que os $3^{\circ}$ anos tiveram mais resistência à nova metodologia no início em função da preocupação com o vestibular e com o Enem, já que estavam acostumados com o modelo e abordagem tradicional de ensino, que possuía a divisão em disciplinas, baseando-se "na exposição verbal da matéria" que é realizada pelo professor, dando

\footnotetext{
${ }^{2}$ Que será detalhada no decorrer do artigo.

${ }^{3}$ Presente através do modelo de escola tradicional utilizado até 2017, que será discutido posteriormente na escola A.
} 
"ênfase nos exercícios, na repetição de conceitos ou fórmulas e na memorização" que "visa disciplinar a mente e formar hábitos" (Leão, 1999, p. 192). Assim como ocorreu com os demais grupos, foram observados espaços de diálogo com conversa e trocas entre alunos e professores em sala de aula e no momento do projeto "mãos dadas".

Além disso, no primeiro dia de observação a coordenadora do ensino médio chamava pequenos grupos de alunos dos $3^{\circ}$ anos para ouvi-los a respeito da nova proposta inserida, trazendo pontos positivos e negativos (diário de campo, 21/03/2018) No decorrer do semestre os processos foram se ajustando e os alunos souberam conciliar e compreender a proposta de acordo com seus objetivos de vida, percebendo que com esse método conseguiriam aprender e conectar mais coisas com o seu cotidiano, isto é, estavam construindo cidadania. Entretanto, vale ressaltar que as mediações docentes e da coordenação permaneceram constantes no decorrer das observações, já que por vezes ainda ocorriam dificuldades como relatado anteriormente pelos $1^{\circ}$ anos. Dessa forma, percebeu-se o projeto "mãos dadas" como um potencializador para se desenvolver a cidadania, já que havia bastante diálogo sobre o cotidiano dos alunos, tanto no que tange às suas aprendizagens, quanto às relações sociais e afetivas. Uma vez que cada aluno "é diferente e precisa ser tratado em sua individualidade, em sua subjetividade" (Gadotti, 2009, p. 46).

Retomando o quadro 3, verificamos que dentre as discrepâncias no que tange aos processos de ensino que influenciam na formação da/para a cidadania, nos contextos estudados, o que chama mais atenção e também desencadeiam em diferenças no funcionamento das escolas são as metodologias de ensino utilizadas. A escola A se caracterizava por ser tradicional, seguindo esse modelo conhecido e ainda predominante nas escolas, onde "a matéria ou conteúdo da educação consiste de corpos de informação e de habilidades que se elaboraram no passado; a principal tarefa da escola é, portanto, transmiti-los à nova geração" (Dewey, 1976, p. 4). Visando "disciplinar a mente e formar hábitos", sendo que "predomina a autoridade do professor que exige atitude receptiva dos alunos" (Leão, 1999, p. 192). Portanto, “a atitude dos alunos, de modo geral, deve ser de docilidade, receptividade e obediência", bem como foi observado nesse contexto pesquisado (Dewey, 1976, p. 5).

A escola A estudada se caracterizou como a "típica sala de aula tradicional, com as suas fileiras de carteiras" e rígidas normas de conduta, representando uma grande "restrição à liberdade intelectual e moral [...] liberdade de pensar, desejar e decidir (Dewey, 1976, p. 59). Dessa forma, percebe-se nesse ambiente uma continuação do padrão de escola reconhecido pela sociedade que tornou a escola universal e gratuita e que identifica como seu papel a "preparação intelectual e moral dos alunos para assumir sua posição na sociedade" (Leão, 1999, p. 192).

Criando, portanto, uma cultura escolar, através de um conjunto de dizeres e fazeres dos principais protagonistas que fazem parte desse contexto, como apontam Malikoski e Kreutz (2014) e Pinto (2014). Nesse caso, a cultura escolar estava fortemente ligada à instituição escola em si e seu funcionamento, tomando como base a abordagem e método tradicional de ensino. Apesar dos avanços no discurso e nos documentos que regem a educação nacional e no próprio PPP da escola (que será apresentado na sequência), que incorporam termos e conceitos como autonomia, desenvolvimento integral do aluno e papel ativo no processo de aprendizagem, "entre outros jargões conceituais que hoje invadem os currículos dos sistemas educacionais", ainda percebe-se um distanciamento da realidade, uma vez que "as relações teórico-metodológicas na práxis didático-pedagógica da escola, em essência, estão estruturadas pelos preceitos da escola tradicional" (Clarindo; Miller, 2018, p. 247). Por isso que, ao entrar nesse espaço, não sentimos nenhum estranhamento quanto ao seu funcionamento, pois estamos adaptados e acostumados com esse tipo de escola que faz parte dessa cultura e modelo já estabelecidos.

Entretanto, visando a formação para a cidadania é necessária uma descontinuação desse ensino tradicional e um reposicionamento epistemológico e pedagógico (Alencar, 2006). Nessa perspectiva, vale lembrar que alguns estudiosos como Dewey (1959) e Freire (2009) ressaltam há um bom tempo a necessidade da superação da educação bancária e tradicional (predominantemente na escola A), sugerindo um enfoque na aprendizagem do aluno, através do seu envolvimento, da sua motivação e do diálogo. As proposições desses autores compuseram este estudo, já que a escola B pesquisada colocou em 
prática, em 2018, o uso das metodologias ativas e colaborativas, que trabalham na perspectiva do diálogo e colocam o aluno como central no processo de ensino-aprendizagem, "enquanto os professores são mediadores ou facilitadores do processo" (Lovato et al., 2018, p. 157). E para que isso aconteça "exige-se a adoção de procedimentos e metodologias inovadoras, diferenciadas, mais criativas, que trabalhem com as múltiplas dimensões da nossa humanidade, ainda pouco exploradas num currículo formalista e, na maioria das vezes, meritocrático" (Padilha, 2009, p. 12).

De acordo com Morán (2015, p. 17-18), as metodologias ativas "são pontos de partida para avançar para processos mais avançados de reflexão, de integração cognitiva, de generalização, de reelaboração de novas práticas", sendo que "a melhor forma de aprender é combinando equilibradamente atividades, desafios e informação contextualizada". Essas atividades foram observadas na escola B em estudo, através de projetos que abarcavam problemas que cercam nossa sociedade, em que cada área do conhecimento trazia suas contribuições para se pensar sob diversas óticas, promovendo a contextualização e integração cognitiva, que geravam nos alunos sensibilização, reflexão, criticidade e a busca de soluções de forma criativa e inovadora, elementos essenciais na formação da/para a cidadania.

Com o uso dessas metodologias o aluno é provocado a participar da aula através de trabalhos em grupo ou discussão de problemas, sendo "retirado de uma posição cômoda, puramente receptora de informações, para um contexto em que poderá desenvolver novas competências, se tornando o centro do processo de ensino-aprendizagem" (LOVATO et al., 2018, p. 158). Rompendo, assim, com a ideia de que o aluno é uma "tábua rasa", como nos modelos tradicionais, e valorizando suas vivências, pois a "organização dos grupos e a construção e reconstrução colaborativa a partir do diálogo" contribuem para uma "prática educativa consciente e crítica" (Oliveira; Marques; Schreck, 2017, p. 679). Deste modo,

Ao mestre que liga a educação à experiência atual incumbe tarefa, ao mesmo tempo, mais séria e mais difícil. Cumpre-lhe estar atento às potencialidades contidas na experiência existente para guiar os estudantes a novos campos e usar o conhecimento dessas potencialidades como seu critério para selecionar e organizar as condições que influenciem a presente experiência dos alunos. (Dewey, 1976, p. 78).

Em função disso, no começo da implementação dessa proposta houve muitas dúvidas, anseios e resistência por parte dos alunos, mas após diálogos eles foram entendendo o funcionamento e se engajando nas atividades. Com essa posição central, o aluno desenvolve algumas habilidades, tais como: "a iniciativa, a criatividade, a criticidade reflexiva, a capacidade de autoavaliação, cooperação para se trabalhar em equipe, responsabilidade, ética e a sensibilidade na assistência" (Lovato et al., 2018, p. 158), habilidades essas que foram constatadas no decorrer das observações e, como citado acima, são princípios que compõem a formação da/para a cidadania. Vale destacar que em boa parte das observações os alunos gerenciavam o tempo que destinariam a cada professor/disciplina, já que os docentes ficavam nas salas aguardando os alunos, trabalhando, assim, a autonomia deles, sempre com acompanhamento dos professores e coordenação. Ou seja, os métodos ativos de ensinoaprendizagem contribuem para que o discente seja protagonista do processo de aprender, auxiliando na "construção do conhecimento libertador que proponha a emancipação e a autonomia dos sujeitos educativos" (Oliveira et al., 2017, p. 682). Dessa forma, para Lovato et al. (2018) o ato de aprender se torna um processo reconstrutivo, que permite ao discente estabelecer distintas relações entre fatos e objetos, produzindo ressignificações e reconstruções, colaborando, assim, para a sua aplicação em diversos contextos. Portanto,

A responsabilidade primária do educador não é apenas a de estar atento ao princípio geral de que as condições do meio modelam a experiência presente do aluno, mas também a de reconhecer nas situações concretas que circunstâncias ambientes conduzem a experiências que levam a crescimento. Acima de tudo, deve saber como utilizar as condições físicas e sociais do ambiente para delas extrair tudo que possa contribuir para um corpo de experiências saudáveis e válidas. [...] Esta é outra razão pela qual a educação progressiva será sempre mais difícil de se conduzir do que o sistema tradicional. (Dewey, 1976, p. 32-33). 
Dando sequência aos achados do estudo, trazemos aqui o que apontam os documentos das escolas no que diz respeito aos objetivos e sua vinculação com a cidadania. $\mathrm{Na}$ escola A, apesar de ter como uma das metas "contribuir para o desenvolvimento do educando, ampliando suas possibilidades de interagir no meio escolar e social, como um ser autônomo, crítico e participativo" (PPP escola pública, 2017, p. 47), não foi possível visualizar a cidadania como um foco de mobilização de todos os envolvidos. O que predomina são práticas mais voltadas para o ensino de conteúdos e preparação para o trabalho. Além disso, as próprias regras instituídas como o sinal para entrada, saída, troca de períodos e restrições nas saídas da sala durante horário de aula são lógicas que guardam traços mercadológicos, originários do mundo fabril. Reforçando, assim, o papel da escola tradicional que "consiste na preparação intelectual e moral dos alunos para assumir sua posição na sociedade" (Leão, 1999, p. 192) e, também, o papel da escola pública para a classe popular, que de forma geral prepara sujeitos para o trabalho. De acordo com Dewey (1976, p. 4-5) o principal propósito ou objetivo é "preparar o jovem para as suas futuras responsabilidades e para o sucesso na vida, por meio da aquisição de corpos organizados de informação e de formas existentes de habilitação, que constituem o material de instrução".

Refletindo sobre a mobilização dos docentes na busca do desenvolvimento da cidadania, precisamos entender que tal prática é delicada, pois muitos professores trabalham geralmente em mais de uma escola, tornando um encontro entre equipe diretiva, coordenação e professores uma tarefa quase impossível (Rifiotis, 2007). Todavia, independentemente disso, não se percebe na prática uma busca coletiva na escola A estudada no desenvolvimento da cidadania, a qual acreditamos neste estudo e que o PPP traz (formar um aluno autônomo, crítico e participativo), mas sim uma compreensão e trabalho coletivo (que cada um faz no individual) no sentido de enquadramento do comportamento social e na busca para a preparação para o trabalho. Um dos fatores que pode influenciar é que na abordagem tradicional do ensino "os conteúdos são separados da experiência do aluno e das realidades sociais", dificultando o desenvolvimento da cidadania como prática cotidiana (Leão, 1999, p. 192). Nesse sentido, concordamos com Gadotti (2009, p. 58-59)

As experiências práticas de Escola Cidadã mostram que o desafio da mudança da escola pública é, ao mesmo tempo, cultural e estrutural. [...] Sem mexer nas estruturas não se muda a escola. Mas também é preciso mexer nas relações sociais e humanas e numa cultura escolar que valorize certo saber e despreze outros. A escola é um espaço de relações socioculturais. A reestruturação física da escola deve associar-se a uma reestruturação espiritual e cultural.

Apesar da dificuldade de encontros coletivos que potencializam a busca por ideais comuns, percebemos através das observações na escola A que muitos professores preferem continuar cada um dentro de seus fazeres, apenas repassando os conhecimentos específicos de suas disciplinas, sem se envolver ou sequer aproximar essa prática à realidade e experiências dos alunos, buscando desenvolver o pensamento crítico, ou seja, formando cidadãos (Rifiotis, 2007). Nesse sentido, uma docente da escola A afirma em sua entrevista que precisam mudar a prática, por exemplo, utilizar mais as tecnologias digitais, mas que os próprios colegas apresentam resistências, dizendo "eu confio no conteúdo no quadro, no caderno, prova e tal porque está ali, o pai vem aqui, ah tu não deu nada, dei sim, está aqui ó, no caderno" (Celia, 12/07/2018). Portanto, percebe-se nesse contexto certo receio por parte dos professores em mudar as práticas, pois elas podem tirar os docentes da "zona de conforto", já que isso demanda transpor com algumas hierarquias, deslocando o professor do papel de único detentor do conhecimento em sala, abrindo espaço para os alunos colaborarem na produção de informações, saberes, conhecimentos e culturas (Bonilla; Pretto, 2015, p. 513). Além disso, "as condições institucionais e a falta de cultura institucional escolar que adote essas ideias", de "um ensino mais humanista e comprometido com a aquisição de valores para o exercício da cidadania", acaba por limitar as potencialidades de propostas inovadoras (Trevisan, 2009, p. 104).

Nessa perspectiva, ficam alguns questionamentos acerca da abordagem e ensino tradicional: do que vale dominar conhecimentos e não saber relacioná-los com o todo, não ter a compreensão da sociedade na qual se está inserido, não ter posicionamento e postura crítica e reflexiva dos fatos? O modelo tradicional e conteudista de ensino, no qual as disciplinas são 
separadas nas "caixas", gera essas conexões necessárias para o uso diário e possibilidade de desenvolvimento e mudança pessoal e social? Ou gera apenas alunos que decoram e reproduzem determinado conhecimento para aplicar na prova e que, anos depois, mal saberão para que serviu? Tais questionamentos já eram realizados por Dewey (1976) e permanecem atuais. O que se tem percebido é que esse modelo exige que os "alunos apenas reproduzam, por meio de procedimentos rotineiros, a informação recebida" (Lima; Cosme, 2018, p. 66), fazendo uma mera transmissão de conteúdos estáticos através de produtos educacionais prontos, na maioria das vezes desconectados de suas finalidades sociais (Clarindo; Miller, 2018). Já que "o estado de segregação em que foi adquirido [o conhecimento] o fez tão desconexo com o restante da experiência, que ele não se apresenta diante das condições reais da vida", ou seja, da prática cotidiana (Dewey, 1976, p. 42).

Assim, é de extrema importância que as instituições de ensino apontem seus projetos pedagógicos para os direitos humanos, não apenas se preocupando com conteúdos e letramento, mas também com a formação do caráter e da personalidade das pessoas, ou seja, com a formação de cidadãos (Brasil, 2013). Logo, entendemos que os direitos humanos estão intrinsecamente ligados à cidadania e ambos aparecem como temas transversais a serem trabalhados na escola, ou seja, que deveriam ser desenvolvidos por todos, mas que, muitas vezes, acabam sendo trabalhados por ninguém. Dentre todas as entrevistas realizadas, apenas a professora de sociologia da escola A aponta essa questão:

Então a escola tem que ter essa percepção, a questão da cidadania, ela vem como eixo transversal já, a ser trabalhado na verdade em todas as disciplinas, porque faz parte do dia a dia de cada pessoa e as situações vão acontecendo. Desta forma, na sala de aula isso também tem que ser implantado, isso tem que ser trabalhado, até porque a gente tem uma sociedade sempre em mudança e a gente tem que ir acompanhando essas mudanças e trazendo o dia a dia do aluno, ele tem que saber contextualizar o que é dado na sala de aula com a realidade dele. Então para que isso aconteça a gente tem que buscar na realidade desse aluno e trabalhar essas questões para que ele possa relacionar e para que ele possa levar esses ensinamentos para a vida dele, enquanto formação do sujeito. (Eliza, 10/07/2018).

Entretanto, por meio das observações realizadas, ficou evidente que essa docente (Eliza) se destacava por isso, não sendo, portanto, uma prática de todos os professores dessa instituição. Portanto, a realidade observada na escola A, no seu funcionamento e na maioria das aulas/disciplinas não condiz com a fala dessa docente, apenas suas próprias aulas e algumas (poucas) práticas de outros docentes seguem o que ela menciona. A docente defende o mesmo que as Diretrizes Nacionais em Direitos Humanos: na escola o cotidiano serve como referência e deve ser analisado, entendido e alterado, pois quando os sujeitos refletem sobre suas experiências e as modificam, por meio da educação dos valores humanísticos, ocorre a conquista do entendimento crítico (Brasil, 2013). Nesse processo, os alunos têm oportunidades contínuas de "atribuir significados às suas práticas e de construir uma compreensão própria do que significa ser um cidadão nos âmbitos local e global, a partir de uma postura de contestação e questionamento dos contextos sociopolíticos e culturais” (Maia; Pereira, 2014, p. 619). Desse modo, a fala e a prática dessa professora de sociologia da escola A vão ao encontro do que apontam as Diretrizes Nacionais em Direitos Humanos (Brasil, 2013) e autores que afirmam que a cidadania ocorre por meio da prática cotidiana (Lopes, 2011; Maia; Pereira, 2014; Menezes; Ferreira, 2014; Rifiotis, 2007).

Já a escola B tem um ensino personalizado que propõe experiências de aprendizagem, através da "solução de problemas, de forma criativa e inovadora, e da comunicação e intervenção em diferentes contextos, usando as várias linguagens (oral, escrita, científica, digital, artística e corporal) e valorizando as múltiplas inteligências" (guia do aluno escola privada, 2018). À vista disso, conforme afirma Piaget (1998, p. 69), os métodos ativos (apresentados como diferenciais da escola) proporcionam um "serviço insubstituível, tanto na educação moral, quanto na educação da inteligência: o de levar a 
criança a construir ela própria os instrumentos que irão transformar, partindo do interior, ou seja, realmente e não mais apenas superficialmente", pois os fatos são descobertos na própria ação, "ao invés de ser recebida inteiramente pronta antes que possa ser compreendida". Nas observações e nas conversas com alguns professores, percebemos através de atividades de resoluções de problemas trazidas pelos docentes que os alunos se envolviam mais, se interessavam e buscavam compreender de fato. Bem como sugere Dewey (1976, p. 81): “o que distingue a educação baseada em experiência da educação tradicional é o fato de que as condições encontradas na experiência atual do aluno são utilizadas como fontes de problemas".

O secretário da escola B afirmou que a participação dos alunos nas salas havia melhorado, porque antes sempre tinha alunos nos corredores e eles tinham que ficar mandando retornar para a sala. O professor de matemática brincou com os alunos (diário de campo, 4/05/2018): "Enganaram vocês né, vocês nunca estudaram tanto, quando vocês ficavam sentados na sala, 10 estudavam e 20 ficavam conversando". O docente comentou que antes se tinha o sistema de turmas, os professores explicavam em sala, baseado num modelo tradicional de ensino. Falou que alguns alunos faziam, prestavam atenção, mas a maioria não fazia nada e ficava incomodando. E agora, este ano, são os mesmos alunos, mas eles sentam e fazem, um que outro não faz e se percebe quando o aluno não quer ele logo sai da sala (diário de campo, 4/05/2018). Nesse caso, identificamos as metodologias ativas e colaborativas de forma positiva tanto no processo de ensino como na formação de um aluno com maior autonomia, mais crítico e reflexivo. Sob esse prisma, Dewey (1976, p. 51) contribui:

Temos, portanto, que concluir que nas chamadas escolas novas, a fonte primária de controle social está na própria natureza do trabalho organizado como um cometimento social, em que todos os indivíduos têm oportunidade de contribuir e pelo qual todos se sentem responsáveis. [...] O educador é responsável pelo conhecimento satisfatório dos indivíduos e das matérias, conhecimento que irá habituá-lo a escolher as atividades suscetíveis de produzir a organização social, em que todos os indivíduos tenham oportunidade de algo contribuir e em que o principal elemento de controle esteja nas próprias atividades por todos partilhadas.

A escola B apresenta no guia do aluno (2018) o perfil do egresso:

O aluno egresso, após concluir o ensino fundamental e o ensino médio, deve ser capaz de questionar, analisar e posicionar-se criticamente no mundo; comunicar-se e intervir em diferentes contextos, usando as várias linguagens (oral, escrita, científica, digital, artística e corporal); solucionar problemas de forma criativa e inovadora; interagir com o outro e suas diferenças; reconhecer, expressar e gerir suas emoções; liderar, empreender e aprender continuamente.

A busca por esse perfil fica evidente em um projeto coletivo, pois nas observações os docentes conversavam bastante entre eles durante o recreio ou em outros momentos, preocupados em desenvolver propostas para atingir esse objetivo. Por isso, os alunos estavam sempre sendo desafiados a refletir sobre suas experiências e as modificar, através da educação dos valores humanísticos e da sensibilização, buscando torná-los mais críticos a partir do tensionamento de seu cotidiano (Brasil, 2013). Ou seja, como comentou um professor de matemática durante as observações, que o mais importante é ensinar coisas para a vida (diário de campo, 17/04/2018). Promovendo a "aprendizagem do sentido das coisas a partir da vida cotidiana, vivenciando processos para abrir novos caminhos, e não apenas para observar o caminho" (Trevisan, 2009, p. 105, grifo da autora). Nas entrevistas também foi muito enfatizada a busca constante da construção do aluno com esse perfil de egresso, demonstrando que o discurso do cidadão que pretendem formar é universal entre docentes e equipe diretiva. $\mathrm{O}$ docente de biologia contribui:

Eu acho que aqui na escola o perfil do egresso ele é bastante presente nas atividades que a gente desenvolve, a gente fala de temas que são polêmicos, a gente fala de coisas que nem sempre são esperançosas, por exemplo, eu nunca deixo de falar nada da minha área, dos problemas ambientais e dos porquês dessas coisas, ainda que dar-se conta disso seja uma coisa meio indigesta. Por exemplo, a grande causa do desmatamento hoje no nosso país é a pecuária, 
isso talvez seja uma coisa meio indigesta, mas é a realidade, isso é o fato e eu faço questão de colocar isso, porque eu acho que isso é importante. Eu acho que se não for pra fazer isso eu nem quero estar aqui. Então nesse sentido eu tenho certeza que a escola aqui contribui para isso, mas ao mesmo tempo eu não acredito que essa seja a norma das outras escolas. Então, na prática, eu não sei se a escola, enquanto instituição, está contribuindo para essa cidadania. Aqui eu vejo acontecer, mas não acredito que isso é geral. (Edvaldo, 9/08/2018).

Dessa forma, percebe-se o comprometimento e princípios que regem a prática docente desse professor, que deveria ser a regra, mas, por diversas questões já explanadas e outras, não é. É importante ressaltar que nessa escola B os docentes têm tardes de planejamento coletivo, o que facilita pensar em propostas articuladas, sendo uma tarde específica para cada ciclo, que no ensino médio é composto por dois $\left(1^{\circ}\right.$ ciclo: $1^{\circ}$ e $2^{\circ}$ anos; $2^{\circ}$ ciclo: $3^{\circ}$ ano). Obviamente, houve um grande investimento por parte da instituição para isso ocorrer, pois a maioria dos docentes trabalha somente nessa escola. Pensando no ensino público, isso seria complicado, pois a realidade recorrente, na maioria das vezes, é a falta de professores. No entanto, é uma possibilidade que não pode ser deixada de lado, uma utopia. Percebe-se, dessa forma,

a importância da interação e inter-relação de aprendizagem e a função do professor, para a manifestação do pensamento crítico dos alunos, na qual os educadores têm papel estratégico e decisivo na inserção de temáticas que englobem as dimensões políticas, sociais, culturais, ambientais entre outras, qualificando os alunos para um posicionamento crítico em face aos dilemas das relações entre homem, sociedade e natureza, tendo como horizonte processos de humanização e de transformação social na formação para cidadania no seu significado mais abrangente. (Marques; Fraguas, 2021, p. 1).

A partir dos achados nesse estudo acerca da cidadania na escola, concordamos com o que Dewey (1976, p. 19, grifo do autor) contribui acerca dessa dicotomia entre a escola tradicional e a nova educação (casos encontrados nesse estudo), o "isto-ou-aquilo". Para ele, a nova educação não nasce da "suposição de que tudo que se exige para a educação nova seja não fazer o que se faz na escola tradicional". Acrescentando que "a nova educação é mais simples do que a tradicional. Está em harmonia com os princípios do crescimento, é algo natural, enquanto na organização tradicional há muito de artificial na seleção e arranjo das matérias". Portanto, "a questão fundamental não é de educação velha versus nova, nem de educação progressiva versus tradicional, mas de alguma cousa - seja qual for - que mereça o nome de educação" (Dewey, 1976, p. 97, grifo do autor).

\section{Conclusão}

Buscando identificar e analisar como as metodologias de ensino e o fazer docente abordam a cidadania em uma escola pública (escola A) e em uma escola privada (escola B) de uma cidade do Vale dos Sinos/RS, foi possível compreender que os métodos de ensino utilizados nas escolas influenciam diretamente na formação para a cidadania, levando às diferenças nos outros aspectos pesquisados. Na escola $\mathrm{A}$, a abordagem e método tradicional prevalece, tornando as conexões, contextualizações, criticidade e reflexões mais limitadas, pois existe a divisão das disciplinas, que muitas vezes não se conversam. Dessa forma, cabe ao docente, dentro de sua disciplina, estar comprometido em promover o exercício da prática cotidiana para se desenvolver a cidadania. Portanto, a busca pela formação da cidadania, nessa escola, se constitui através do enquadramento do comportamento social e na preparação para o trabalho.

Em contrapartida, na escola B, os métodos ativos e colaborativos, desenvolvidos através de atividades de resolução de conflitos, promovem a elaboração de projetos que abarcam todas as áreas do conhecimento, possibilitando, ao aluno, perceber os problemas sob diversas óticas. Formando, dessa forma, um aluno com mais autonomia, mais crítico, mais reflexivo, que se sensibiliza e busca respostas para diversas situações. Ainda assim, percebe-se que nem todos os docentes conseguiam instigar os alunos à reflexão, pois como foi relatado, a escola mudou sua metodologia no ano da pesquisa, 2018, e todos estavam em 
processo de adaptação e aprendizagem, afinal, fomos formados na lógica tradicional e conteudista, e romper com isso é um processo contínuo que requer dedicação e aprendizagem.

Assim sendo, percebe-se que os professores da escola A estavam enraizados a metodologias e formas de ensinar que eles aprenderam na sua formação, ou seja, o método tradicional de ensino-aprendizagem. Enquanto que, na escola B, os alunos estavam sendo demandados a se depararem e se engajarem nessa nova proposta que foi concebida por toda a escola. Reforçando-se, portanto, a importância do Projeto Político-Pedagógico e da formação coletiva no espaço escolar na busca da formação da/para a cidadania (envolvendo equipe diretiva, professores, alunos, funcionários e comunidade), e não apenas ações isoladas por parte de determinadas disciplinas e/ou professores.

A ideia deste texto foi de evidenciar como o tema cidadania é abordado nas escolas, não buscando "disciplinarizar" o tema, mas sim visualizar de forma sistêmica como essa temática é vivenciada dentro do currículo escolar. Propõem-se como estudos futuros investigar também os alunos, pois fazem parte desse processo de formação.

\section{Agradecimentos}

O presente trabalho foi realizado com apoio da Coordenação de Aperfeiçoamento de Pessoal de Nível Superior Brasil (CAPES) - Código de Financiamento 001.

\section{Referências}

Alencar, J. R. S. (2006). A formação para a cidadania em discursos de professores de Física. 2006. 152 f. Dissertação (Mestrado em Ensino e Ciências e Matemáticas) - Universidade Federal do Pará, Belém.

Bonilla, M. H. S. \& Pretto, N. L. (2015). Política educativa e cultura digital: entre práticas escolares e práticas sociais. Perspectiva, 33(2), 499-521.

Brasil. (2013). Secretaria de Direitos Humanos da Presidência da República. Educação em Direitos Humanos: Diretrizes Nacionais. Brasília: Coordenação Geral de Educação em SDH/PR, Direitos Humanos, Secretaria Nacional de Promoção e Defesa dos Direitos Humanos.

Cauduro, M. T. (Org.). (2004). Investigação em Educação Física e Esportes: um olhar pela pesquisa qualitativa. Novo Hamburgo: Feevale.

Clarindo, C. B. S. \& Miller, S. (2018). Atividade de estudo e superação do modelo tradicional de ensino: contribuições davidovianas. Educação em Foco (UEMG), 21(33), 243-262.

Dewey, J. (1959). Vida e Educação. 5. ed. São Paulo: Nacional.

Dewey, J. 1859-1952. (1976). Experiência e educação. Tradução de Anísio Teixeira. 2. ed. São Paulo, Ed. Nacional.

Gadotti, M. (2009). Educação Integral no Brasil: inovações em processo. São Paulo: Editora e Livraria Instituto Paulo Freire.

Freire, P. (2009). Pedagogia da Autonomia. 36. ed, São Paulo: Paz e Terra,.

Leão, D. M. M. (1999). Paradigmas contemporâneos de educação: escola tradicional e escola construtivista. Cadernos de Pesquisa, 107, 187-206.

Lima, L. \& Cosme, A. (2018). Desafios da formação de professores num contexto de mudança paradigmática na educação. Revista Intersaberes, 13(28), 65-76.

Lopes, S. F. (2011). Como se educa o soberano para a democracia? A formação cidadã na escola da rede particular de ensino (uma leitura contemporânea). 2011. 106 f. Dissertação (Mestrado em Educação) - Universidade Federal de Pernambuco, CE, Recife.

Lovato, F. L. et al. (2018). Metodologias Ativas de Aprendizagem: uma Breve Revisão. Acta Scientiae, 20(2), 154-171.

Maia, A. A. M. \& Pereira, M. Z. C. (2014). Cidadania, Educação e Cotidiano. Educação \& Realidade, 39(2), 617-631.

Malikoski, A. \& Kreutz, L. (2014). A Cultura Escolar como categoria de análise na produção de narrativas históricas sobre a Educação. Textura, 32, 245-260.

Marques, R. \& Fraguas, T. A formação do senso crítico no processo de ensino e aprendizagem como forma de superação do senso comum. Research, Society and Development, v. 10, n. 7, e31010716655, 2021.

Menezes, I. \& Ferreira, P. (2014). Cidadania participatória no cotidiano escolar: a vez e a voz das crianças e dos jovens. Educar em Revista, 53, $131-147$.

Morán, J. (2015). Mudando a educação com metodologias ativas. In: Souza, C. A. \& Morales, O. E. T. (orgs.). Coleção Mídias Contemporâneas.

Convergências Midiáticas, Educação e Cidadania: aproximações jovens. Vol. II. PG: Foca Foto-PROEX/UEPG. 
Research, Society and Development, v. 10, n. 10, e240101018777, 2021

(CC BY 4.0) | ISSN 2525-3409 | DOI: http://dx.doi.org/10.33448/rsd-v10i10.18777

Oliveira, C. M., Marques, V. F. \& Schreck, R. S. C. (2017). Aplicação de metodologia ativa no processo de ensino-aprendizagem: relato de experiência. Rev. Eletrônica Pesquiseduca, 9(19), 674-684.

Padilha, P. R. (2009). Prefácio. In: Gadotti, M. Educação Integral no Brasil: inovações em processo. São Paulo: Editora e Livraria Instituto Paulo Freire.

Piaget, J. (1998). Para onde vai a educação? 14. ed. Rio de Janeiro: José Olympio.

Pinto, N. B. (2014). História das disciplinas escolares: reflexão sobre aspectos teórico-metodológicos de uma prática historiográfica. Rev. Diálogo Educ., $14(41), 125-142$.

Pereira, E. A. \& Silva, E. L. (2008). Educação, ética e cidadania: a contribuição da atual instituição escolar. Revista Eletrônica de Educação, 2(1), $26-32$.

Rifiotis, T. (2007). Sujeito de direitos e direitos do sujeito. In: Silveira, R.M.G. et al. Educação em Direitos Humanos: fundamentos teórico-metodológicos. João Pessoa, Editora Universitária. p. 231-244.

Silverman, D. (2009). Interpretação de dados qualitativos: métodos para análise de entrevistas, textos e interações. Porto Alegre: Artmed.

Trevisan, I. (2009). Práticas de cidadania em narrativas de professores de ciências: trabalho coletivo de ensino e de aprendizagem. 2009. 119 f. Dissertação (Mestrado em Educação em Ciências e Matemáticas) - Universidade Federal do Pará, Instituto de Educação Matemática e Científica, Belém.

Vinuto, J. (2014). A amostragem em bola de neve na pesquisa qualitativa: um debate em aberto. Temáticas, 22(44), 203-220. 